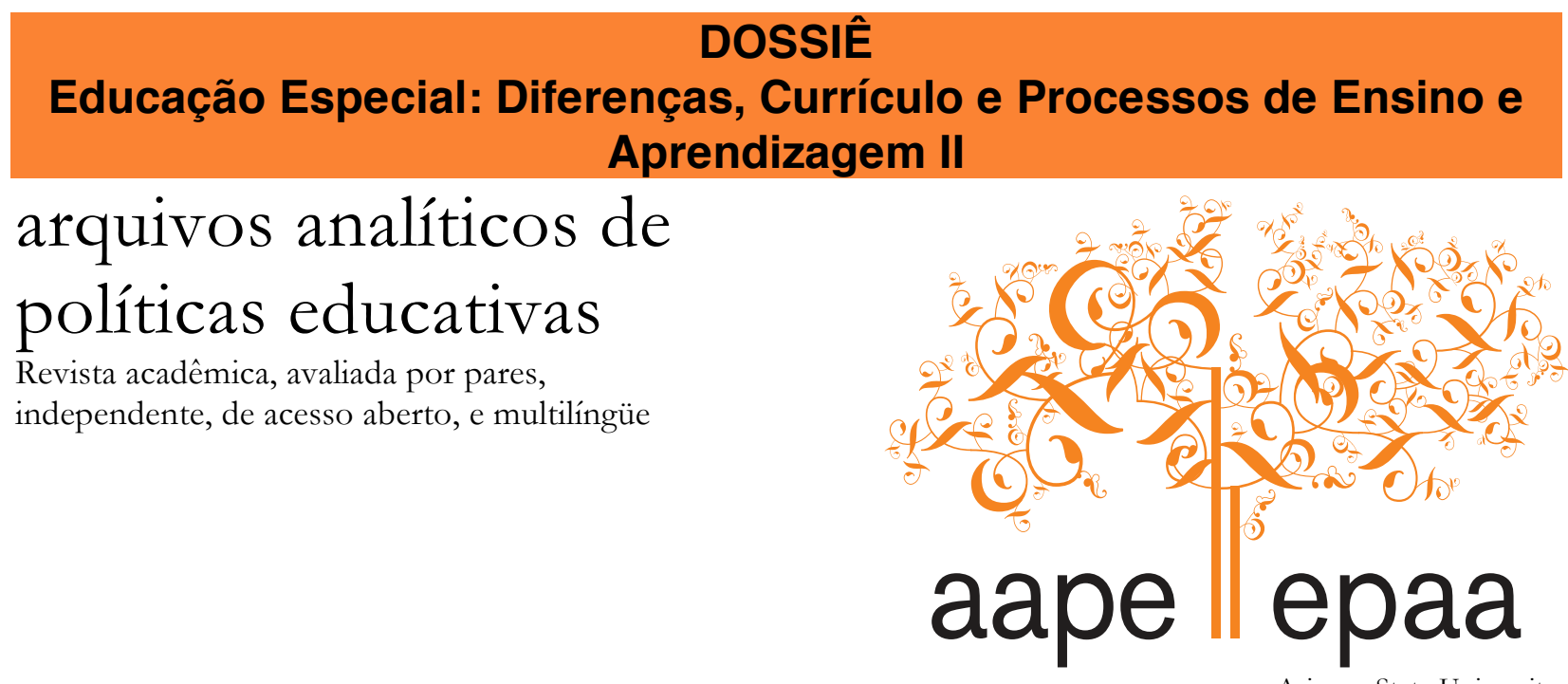

Arizona State University

Volume 23 Número 35

16 de março de 2015

ISSN 1068-2341

\title{
Educação Especial na Perspectiva Inclusiva: Implicações para o Trabalho Docente Articulado no Ensino Médio e Tecnológico
}

\author{
Fabiane Adela Tonetto Costas \\ \& \\ Cláucia Honnef \\ Universidade Federal de Santa Maria \\ Brasil
}

Citação: Costas, F. A. T., \& Honnef, C. (2015). O trabalho docente articulado como proposta pedagógica para educação especial na perspectiva inclusiva no ensino médio e tecnológico. Arquivos Analiticos de Políticas Educativas, 23(35). Dossiê Educação Especial: Diferenças, Currículo e Processos de Ensino e Aprendizagem II. Editoras convidadas: Márcia Denise Pletsch \& Geovana Mendonça Lunardi Mendes. http://dx.doi.org/10.14507/epaa.v23.1632

Resumo: O trabalho docente articulado é proposto como uma adaptação ao ensino colaborativo e prevê o trabalho conjunto entre professores da classe comum e professores de Educação Especial no planejamento, no desenvolvimento e na avaliação da aula. O objetivo deste estudo foi analisar como os professores do Ensino Médio e Tecnológico de um Instituto Federal de Educação no Rio Grande do Sul, Brasil, percebem o trabalho docente articulado, quais suas limitações e possibilidades, diante da inclusão de alunos com deficiência e/ou necessidades educacionais especiais (NEE), intensificada a partir da Política Nacional da Educação Especial (Brasil, 2008). A investigação foi qualitativa, com uso de diário de campo e um questionário respondido por sete professores de um aluno com deficiência mental incluído no ensino médio e tecnológico. Para a interpretação dos dados, utilizou-se a Análise de Conteúdo. Os resultados evidenciaram que o 
trabalho docente articulado é importante. Porém, poucos professores participantes da pesquisa citaram dificuldades para sua realização, evidenciadas pelo baixo número de professores de Educação Especial e de classe comum e o pouco tempo para realização desse trabalho. Concluiu-se que o trabalho docente articulado tem obstáculos a superar, no entanto, acredita-se no seu potencial para mobilizar a aprendizagem, principalmente, dos alunos com deficiência/NEE, frente à Educação Especial na perspectiva da educação inclusiva, a qual, no contexto educacional atual, massificou a ideia de inclusão educacional escolar, sem haver, ainda, investimentos suficientes que garantam condições para que ela possa ser estendida a todos os sujeitos.

Palavras-chave: educação especial; educação inclusiva; trabalho docente articulado

\section{Special Education in Perspective: Implications for Articulated Teaching in High School and Technological}

Abstract: Articulated teaching is proposed as an adaptation to collaborative teaching and aims the joint work between the regular class teacher and the special education teacher in planning, developing and evaluating a class. The aim of this study was to analyze how high school teachers and technology education teachers of a Federal Education Institute in Rio Grande do Sul, Brazil, realize articulated teaching, what their limitations and possibilities are before the inclusion of students with disabilities and/or special educational needs, intensified after the National Policy of Special Education (2008). The research was qualitative, using a field diary and a questionnaire answered by seven professors from a student with intellectual disabilities included in the medium and technology education. To interpret the data we used in Content Analysis. The results showed that articulated teaching is important, however, few teachers have cited difficulties in performing it, for example, the low number of special education teachers and regular class teachers, and little time to this work. We conclude that the articulated teaching has obstacles to overcome, but we believe in its potential to mobilize learning, particularly for pupils with special educational needs, through special education in the perspective of inclusive education, which in the current educational context massified the idea of inclusive school education, with no sufficient investment to ensure conditions for it to be extended to all subjects.

Keywords: special education; inclusive education; articulated teaching

\section{La Educación Especial en la Perspectiva Inclusiva: Implicaciones para el Trabajo Docente Articulado en la Escuela Secundaria y Tecnológica}

Resumen: El trabajo docente articulado se propone como una adaptación a la enseñanza colaborativa y prevé un trabajo conjunto entre profesores y maestros de clases regulares de educación especial en la planificación, desarrollo y evaluación de la lección. El objetivo de este estudio fue analizar cómo los profesores de secundaria y un Instituto Tecnológico Federal de Educación, en Río Grande do Sul, Brasil, danse cuenta de la labor docente articulado, cuáles son sus limitaciones y posibilidades, delante de la inclusión de los alumnos con discapacidades y / o necesidades educativas especiales (NEE), realzadas por la Política Nacional de Educación Especial (Brasil, 2008 ). La investigación fue de tipo cualitativo, utilizando un diario de campo y un cuestionario respondido por siete profesores de un estudiante con discapacidad mental incluido en la secundaria de enseñanza tecnologica. En la interpretación de los datos, se utilizó el análisis de contenido. Los resultados mostraron que el trabajo de la enseñanza articulado es importante. Sin embargo, pocos de los profesores participantes citaron dificultades en su implementación, como lo demuestra el bajo número de profesores de educación especial y regular de clase y poco tiempo para realizar esta tarea. Se concluyó que la labor docente articulado tiene obstáculos que superar, sin embargo, creemos en su potencial para movilizar el aprendizaje, especialmente para los alumnos con NEE bajo la Educación Especial en la perspectiva de la educación inclusiva, la cual, en el 
contexto educativo actual, hay masificado la idea de la inclusion escolar, sin más inversiones para garantizar condiciones suficientes para que se extienda a todos los sujectos.

Palabras clave: educación especial; educación inclusiva; enseñanza articulada

\section{Introdução}

Em janeiro de 2008, a Nova Política de Educação Especial na Perspectiva da Educação Inclusiva (Brasil, 2008) foi promulgada, e as orientações sobre da Educação Especial no Brasil sofreram modificações. Essa nova política tem como escopo o acesso, a participação e a aprendizagem dos alunos com deficiência, transtornos globais do desenvolvimento e altas habilidades/superdotação nas escolas regulares, garantindo o atendimento educacional especializado, a continuidade da escolarização, a formação de professores especializados para esse atendimento, a participação da família, da comunidade, a acessibilidade urbana, arquitetônica, nos transportes, nos mobiliários, na comunicação e na informação.

Desse modo, encontrar estratégias de ensino para alunos com deficiência e/ou necessidades educacionais especiais ${ }^{1}$ não é uma tarefa simples, pois exige, dos professores tanto de Educação Especial quanto de classe comum, a observação e a consideração de características individuais e coletivas, aspectos ambientais e sociais. Esses aspectos eram pouco sopesados anteriormente à inserção dos alunos com deficiência e/ou NEE nas salas de aula comuns.

Os professores de classe comum, mesmo hoje observando, em sua formação inicial, alguns aportes sobre o trabalho com alunos com deficiência e/ou NEE, geralmente, apresentam-se inseguros, ansiosos e, muitas vezes, angustiados (Naujorks, Pletsch, \& Kempfer, 2000) ao receberem esses estudantes em sala de aula. Os professores de Educação Especial, que, por muito tempo, trabalharam em escolas e classes especiais, também apresentam tais sentimentos (ibidem).

Com isso, acredita-se que um trabalho conjunto entre os professores de Educação Especial e de classe comum pode ser benéfico a ambos, pois as aflições e incertezas podem ser divididas. Além disso, a responsabilidade de construir estratégias de ensino aos alunos com deficiência e/ou NEE, atendendo às adaptações necessárias as suas especificidades de ensino-aprendizagem e a dos demais estudantes, pode ser compartilhada e, assim, o trabalho pode ser mais eficiente e satisfatório.

Para se estabelecer essa parceria, existe a proposta do ensino colaborativo, que se pensa adequado aos anos iniciais, mas não aos anos finais do Ensino Fundamental, bem como ao Ensino Médio ou médio técnico, visto que nestes níveis de ensino não há a unidocência, havendo necessidade de articulação do professor de Educação Especial com professores de diferentes áreas do conhecimento. Para esses níveis, propõe-se o trabalho docente articulado, pesquisado em estudo que objetivou verificar e analisar os limites e as possibilidades que docentes da educação profissional e tecnológica percebem acerca do trabalho docente articulado, tendo, no cenário, uma nova política

\footnotetext{
${ }^{1}$ Nos documentos oficiais afetos à área da Educação Especial, encontram-se as seguintes expressões para nomear os alunos atendidos pela educação especial: pessoas portadoras de necessidades educacionais especiais; pessoas com necessidades educacionais especiais, e, mais recentemente, pessoa com deficiência. Optamos por fazer uso do conceito de Costas (2013), combinando as definições em "pessoa com deficiência e/ou necessidades educacionais especiais", porque nem toda pessoa com deficiência* tem alguma necessidade educacional especial e, por outro lado, nem toda pessoa com necessidades educacionais especiais tem alguma deficiência. A pessoa com necessidades educacionais especiais é aquela que apresenta, de modo permanente ou transitório, algum(a) dificuldade/transtorno na sua aprendizagem ou, ainda, aquela que, por sua elevada capacidade de aprendizagem, apresenta algum tipo de dificuldade escolar.

*Conforme Decreto 3.988/1999, entende-se deficiência como a perda ou anormalidade de alguma estrutura ou função psicológica, fisiológica ou anatômica que gere incapacidade para o desempenho de atividade, dentro do padrão considerado normal para o ser humano. Temos deficiência sensorial: deficiência física, deficiência metal, deficiência múltipla.
} 
para a Educação Especial. Um questionário e o diário de campo foram os instrumentos que compuseram os dados desta pesquisa e, para a interpretação dos dados, empregou-se a técnica de Análise de Conteúdo (Bardin, 2008).

Assim, este texto apresenta a proposição do trabalho docente articulado, enfatizando a análise das percepções dos docentes sobre tal forma de interlocução e finaliza com alguns apontamentos sobre o que seria necessário para efetivação dessa prática.

\section{Do Ensino Colaborativo ao Trabalho Docente Articulado}

Para a efetivação da Educação Especial nas escolas e classes regulares, encontram-se apontamentos referentes à necessidade de uma atuação articulada entre a Educação Especial e o ensino comum. Esses apontamentos estão em documentos legais, como nas Diretrizes Nacionais da Educação Especial na Educação Básica, instituídas pela Secretaria de Educação Especial, em 2001, que estabelecem: "A inclusão de alunos com necessidades educacionais especiais em classes comuns do ensino regular [...] exige interação constante entre o professor da classe comum e de serviços de apoio pedagógico especializado" (Brasil, 2001, p. 51, grifo nosso).

Observa-se que o documento menciona a necessidade de "interação constante" entre o ensino comum e a educação especial para que os alunos, público da Educação Especial, possam lograr um bom rendimento escolar. Essa interação pode acontecer nos anos finais do ensino fundamental através do trabalho docente articulado.

A Política Nacional da Educação Especial na Perspectiva da Educação Inclusiva, instituída pela Secretaria de Educação Especial em 2008, apresenta que: [...] a educação especial atua de forma articulada com o ensino comum, orientando para o atendimento às necessidades educacionais especiais desses alunos (Brasil, 2008, p. 15, grifo nosso).

Neste documento verifica-se uma menção ao trabalho da Educação Especial que necessita estar articulado ao ensino comum, proporcionando orientações referentes ao atendimento as NEE dos alunos. Essas orientações podem ocorrer principalmente no planejamento da aula de forma articulada entre os professores de Educação Especial e de classe comum, mas também no desenvolvimento da aula e avaliação dos alunos, com o trabalho docente articulado.

As Diretrizes Operacionais para o Atendimento Educacional Especializado (AEE) na Educação Básica, modalidade de Educação Especial- instituídas pela Resolução no 4 do Conselho Nacional da Educação, em 2009, em seu artigo $9^{\circ}$ trazem que:

São atribuições do professor do Atendimento Educacional Especializado: [...]

estabelecer articulação com os professores da sala de aula comum, visando à disponibilização dos serviços, dos recursos pedagógicos e de acessibilidade e das estratégias que promovem a participação dos alunos nas atividades escolares. (Brasil, 2009, pp. 2-3, grifo nosso)

Nos documentos mencionados acima, o modo e as condições para acontecer a articulação entre os professores de Educação Especial e de classe comum não estão especificados. Entende-se que a atuação articulada precisa acontecer de forma que os fazeres e saberes tanto dos professores de Educação Especial quanto dos professores da classe comum possam se complementar na busca pelo desenvolvimento dos alunos com deficiência e/ou NEE e, também, dos demais, sendo o trabalho docente articulado e o ensino colaborativo alternativas para a articulação referida nos documentos supracitados.

O ensino colaborativo ganha ênfase em pesquisas acadêmicas a partir da proposta de inserção de alunos com deficiência e/ou NEE nas escolas e classes comuns. Nele, os professores de Educação Especial e de classe comum trabalham juntos no planejamento e no desenvolvimento das 
aulas e na avaliação dos alunos, principalmente daqueles que são o foco do trabalho em parceria entre os docentes (Capellini, 2004; Devéns, 2007; Fontes, 2008; Zanatta, 2004).

Capellini (2004) explicita que o ensino colaborativo é uma fusão de professores da educação comum e especial para buscar estratégias pedagógicas de ensino, para ajudar no atendimento a alunos com deficiência e/ou NEE em classes comuns. Conforme a autora, no ensino colaborativo, os docentes envolvidos, que possuem conhecimentos, experiências e habilidades de trabalho distintas, juntam-se em cenários pedagógicos, de forma colaborativa, para ensinar a grupos heterogêneos tanto questões acadêmicas de conteúdo quanto comportamentais. Capellini (2004, p. 88) ainda aponta que ambos os tipos de docentes "[...] compartilham a responsabilidade de planejar e de implementar o ensino e a disciplina da sala de aula".

Também Mendes (2006) traz esclarecimentos sobre o que significa o ensino colaborativo: Em síntese, o ensino colaborativo ou co-ensino, é um modelo de representação de serviço de Educação Especial no qual o educador comum e o educador especial dividem a responsabilidade de planejar, instruir e avaliar a instrução de um grupo heterogêneo de estudantes, sendo que esse modelo emergiu como uma alternativa aos modelos de sala de recursos, classes especiais ou escolas especiais, e especificamente para responder as demandas das práticas de inclusão de estudantes com necessidades educacionais especiais. (p. 32)

Tomando por base o acima apresentado, no ensino colaborativo, os professores da classe comum e de Educação Especial trabalham coletivamente em três momentos, ou seja, dividindo a responsabilidade no planejar, no desenvolver a aula e no avaliar o processo de ensino-aprendizagem.

Mendes (2006) se refere ao ensino colaborativo como um modelo de representação do serviço de Educação Especial e acredita-se pertinente destacar que se percebe a Educação Especial como uma modalidade de ensino que pode se desenvolver em instituições especializadas, como centros de atendimentos, Associações de Pais e Amigos dos Excepcionais (APAES). Contudo, com a inserção de seu público-alvo em escolas regulares, também perpassa e se necessita dialogar com os diferentes níveis e modalidades de ensino, como a educação básica, a profissional e tecnológica, a superior, e desenvolver ações que agreguem na promoção de ensino-aprendizagem aos alunos com deficiência e/ou NEE.

Gately e Gately (2001, apud Assis, Mendes e Almeida, 2011) apresentam três diferentes estágios de interação e de colaboração dos professores no ensino colaborativo:

No estágio inicial, os professores se comunicam superficialmente na tentativa de estabelecer uma relação. Assim, existe, nesse momento, a necessidade de compreender o desenvolvimento do processo para que não fiquem estagnados nesse primeiro estágio. O segundo estágio é o de comprometimento e, nesse nível da relação, a comunicação dos professores é mais frequente, aberta e interativa, o que possibilita que eles construam a confiança necessária para trabalhar na perspectiva da colaboração. No estágio final, ou seja, no estágio propriamente colaborativo, os professores se comunicam e interagem abertamente, trabalham juntos e complementam um ao outro. (p. 3)

Observa-se que existem níveis de interação ou colaboração a serem alcançados para se conseguir que o ensino colaborativo seja complementar e benéfico tanto para os alunos como para os professores.

As pesquisas aqui citadas sobre ensino colaborativo (Capellini, 2004; Devéns, 2007; Fontes, 2008; Mendes, Assis, \& Almeida, 2011; Zanatta, 2004) aconteceram em âmbito de anos iniciais do Ensino Fundamental. Porém, experiências profissionais em uma realidade educacional em nível médio e tecnológico, no Instituto Federal Farroupilha - IFFarroupilha - Campus São Borja, no estado do Rio Grande do Sul (RS), Brasil possibilitaram a verificação de que, nos anos finais do Ensino Fundamental e no Ensino Médio, a realidade de atuação docente é outra, visto que não se 
tem mais somente um professor em sala de aula, mas sim vários docentes ministrando diferentes conteúdos.

Nos anos finais do Ensino Fundamental, no Ensino Médio ou médio técnico, tendo por base as vivências nessa etapa de ensino, entende-se que nem sempre seja necessário o professor de Educação Especial estar junto ao professor da classe comum durante todo o tempo em sala de aula. Aliás, nesse nível de ensino, tem-se maior número de professores por turma. Estes professores, apesar de ministrarem classes em muitas turmas, muitas vezes, têm um contato mais reduzido com cada turma, ou seja, permanecem alguns períodos do turno em contato com suas turmas. Assim, nem sempre necessitam do professor de Educação Especial auxiliando-os diretamente em sala de aula, mas sim precisam mais especificamente do apoio deste no planejamento das aulas, para que as atividades contemplem as especificidades do aluno com deficiência e/ou NEE.

Propôs-se, então, uma adaptação do ensino colaborativo para o trabalho docente articulado, tendo como premissa essencial a convergência entre o trabalho desenvolvido pelos professores de Educação Especial e pelos professores da classe comum, no que tange aos objetivos traçados para o aluno com deficiência e/ou NEE, bem como em relação às ações desenvolvidas para o alcance destes objetivos tanto em classe comum como na sala de recursos.

O trabalho docente articulado se apresenta distinto do ensino colaborativo apenas devido ao fato de não, necessariamente, os dois professores precisarem estar sempre juntos na classe comum. Porém, o planejamento, a avaliação e os estágios (Mendes, 2006) do ensino colaborativo podem se aplicar também ao trabalho docente articulado.

Com essa proposição, desde abril de 2012, tem-se buscado desenvolver no IFFFarroupilha, o trabalho docente articulado com os professores de um aluno do primeiro ano do Ensino Médio Integrado ao Curso Técnico em Informática, que possui diagnóstico médico de deficiência mental, denominado aqui de A1. Foram convidados a participar do estudo os onze professores de A1, sendo que sete deles, com idade entre vinte e cinco e trinta e oito anos, responderam ao questionário utilizado para coleta de dados. Além do questionário, a investigação teve como base, também, o diário de campo, no qual estão relatadas percepções acerca da Educação Especial na perspectiva da educação inclusiva e do trabalho docente articulado no Instituto.

Os resultados da pesquisa foram divididos em categorias de análise pela enunciação, conforme a metodologia de Análise de Conteúdo proposta por Bardin (2008). Pela extensão dos resultados optou-se por apresentar a categoria que refere especificamente sobre o trabalho docente articulado, visto que ele foi foco do estudo desenvolvido.

\section{Trabalho Docente Articulado: Abrangência e Potencialidade}

O trabalho docente articulado consiste numa prática pedagógica que pressupõe parceria entre professores de Educação Especial e comum, para a efetivação da inclusão educacional escolar ${ }^{2}$ de alunos com deficiência e/ou NEE. Essa parceria acontece no planejar a aula, no desenvolvê-la com os dois docentes em sala de aula, caso o professor de classe comum julgar necessário, e ocorre, também, na avaliação do aluno A1, destacado neste texto.

\footnotetext{
2 É importante destacar que há diferenças de significado entre inclusão escolar e inclusão educacional escolar. A primeira, segundo Carvalho (2006), pode ser compreendida como a simples presença física do aluno com deficiência e/ou NEE na escola. Já o termo inclusão educacional escolar, remete ao processo de inclusão no espaço escolar que não se limita a presença física do educando acima referido. Ele implica na mobilização pelo desenvolvimento do processo de ensino aprendizagem dos alunos com deficiência e/ou NEE e tudo que nele é envolvido, o respeito e consideração ao educando, fornecimentos de materiais e recursos necessários a aprendizagem, garantia da participação do aluno como sujeito ativo na instituição.
} 
Assim, apresenta-se, neste espaço, a percepção dos professores sobre o trabalho docente articulado e seus três momentos: o planejamento articulado entre o professor de Educação Especial e professor da classe comum, o desenvolvimento da aula por ambos e a avaliação em conjunto entre eles. Para garantir sigilo da identidade dos sete participantes do estudo, estes são aqui nominados de P1, P2, P3, P4, P5, P6 e P7.

Sobre o planejamento articulado, todos os sete professores o descreveram como sendo "Interessante ${ }^{3}$ [...]" (P2) e "Importante [...]" (P6), pois “[...] esses profissionais (professores de Educação Especial) colaboram com seu conhecimento, 'emprestando' um olhar mais aprofundado aos docentes de disciplinas específicas, sobre os alunos com necessidades educacionais especiais" (P2); "Articula-se formas diferenciadas de preparos pedagógicos" (P7); "Acredito ser positivo e benéfico ao aluno" (P4); "Acho bastante interessante com relação à inclusão deste aluno na sala de aula e a socialização com os demais" (P5). Também, "Esse planejamento auxilia para uma melhor compreensão de atividades que sejam coerentes para o aluno. E também as dúvidas que surjam durante o planejamento, que os objetivos sejam alcançados" (P1).

No meu ponto de vista, essa perspectiva só vem a somar com a temática colaborativa visando a atitudes inclusivas, uma vez que se trata de uma tarefa não tão fácil de realizar na prática, mas que, com a soma de esforços e conhecimentos, acaba por se tornar menos difícil e mais prazerosa tanto ao aluno como para o docente. (P3)

As palavras dos docentes falam da relevância que atribuem ao planejamento de forma articulada com os profissionais de Educação Especial. Inclusive, alguns professores manifestam que o planejamento e o trabalho em parceria auxiliam professores e alunos. Pelo indicado é possível afirmar que os momentos de planejamento em conjunto entre os docentes tornam a educação de alunos com deficiência e/ou NEE em espaços regulares de ensino, um desafio menos complicado, mais prazeroso, fazendo com que a adaptação de objetivos e metodologias e o seu consecutivo repensar aconteça dividindo-se responsabilidades entre os professores. Assim, a parceria permite maiores possibilidades de sucesso na promoção da aprendizagem de alunos com deficiências e/ou NEE, como refere Capellini (2004).

É importante frisar que, quando da proposição do trabalho docente articulado aos professores do IFFarroupilha - Campus São Borja, não se discutiram ou aprofundaram as consequências, os pontos positivos ou negativos dessa prática; simplesmente, foi apresentado, aos docentes, o que consiste esse trabalho e eles o aceitariam desenvolver. Portanto, os entendimentos que os docentes expõem não possuem qualquer influência de discussões prévias sobre o trabalho docente articulado e sua realização.

Voltando ao apresentado pelos professores, é interessante atentar para as colocações de P4 e P5, pois a primeira professora aponta o benefício do planejamento articulado somente aos alunos, mas, em momentos de planejamento articulado com a professora de Educação Especial, P4 expõe a importância desse momento para sua formação enquanto docente. Tal colocação reafirma o pontuado pelas pesquisas desenvolvidas no Brasil sobre o ensino colaborativo, já citadas neste texto, as quais mostram melhor desenvolvimento tanto dos alunos como dos professores no que tange a sua formação pessoal e profissional a partir da realização de um trabalho articulado. Porém, ele só acontece se existirem condições para fazê-lo e se os professores puderem e decidirem realizá-lo.

Como se percebe no relato de P5, ele acredita que o planejamento de forma articulada entre os docentes seja importante para a inclusão do aluno em sala de aula e para a socialização com os demais. Verifica-se, aqui, bastante presente, ainda, a ideia de que a inclusão educacional escolar colabora para a socialização do aluno com deficiência e/ou NEE, e vale destacar que P5 é um

\footnotetext{
${ }^{3}$ Estas palavras destacadas, bem como as demais que se seguem estão em negrito, pois embasaram a escolha das respectivas categorias.
} 
docente da área técnica, que, antes de trabalhar no Instituto, não obteve formação/informação sobre como trabalhar com estudantes foco do trabalho docente articulado. Talvez por esse motivo e por expressar não ter grandes expectativas em relação ao desenvolvimento de A1, P5 associe a inserção desse aluno na escola e na classe comum, basicamente, à socialização.

No que tange às percepções dos professores referentes ao desenvolvimento da aula de forma colaborativa, P4 não se manifestou, e os demais expressaram que: “Também é importante" (P6); "Importante, pois permite prever e reconhecer as dificuldades" (P7); "Tendo o apoio do profissional de Educação Especial se torna mais fácil" (P5); "Assim como no planejamento, talvez a execução do que for planejado possa ser otimizada no caso de uma atuação conjunta professor/ educador especial." (P2); "Seria mais produtivo, pois os alunos com deficiências e/ou necessidades educacionais especiais teriam um acompanhamento mais de perto, conseguindo desta forma perceber melhor as dificuldades do mesmo em aula, referentes aos conceitos desenvolvidos em aula" (P1).

Assim como a soma é positiva ao planejamento, acredito que na prática possa ter a mesma recíproca, onde docente e profissional de Educação Especial possam discutir o que vem dando certo, bem como realizar ajustes em suas práxis, visto que todo planejamento educacional apresenta uma certa flexibilidade. (P3)

Novamente, verifica-se que os docentes consideram relevante o desenvolvimento da aula de forma articulada. Eles acreditam que, com esse trabalho, ela é potencializada, bem como é potencializada a aprendizagem dos alunos e a possibilidade de discutir e repensar a práxis, como menciona P3, a qual é entendida como o elo entre teoria e prática que gera a ação movida por intencionalidade a partir de uma abordagem teórica. ${ }^{4}$

Também é importante evidenciar o pontuado por P5, pois o que esse professor afirma reitera e valida uma premissa presente na pesquisa, de que ter um profissional de Educação Especial na instituição de ensino, apoiando os docentes, torna o trabalho frente à Educação Especial na perspectiva inclusiva mais fácil, porém, não torna menos necessária a colaboração de todos os envolvidos no contexto escolar, como apresenta Sant'Ana (2005).

Outro aspecto a ser destacado da percepção dos docentes diz respeito à questão de que o desenvolvimento da aula de forma articulada possibilitaria maior atenção ao aluno com deficiência e/ou NEE e a percepção de suas dificuldades. Essa colocação pode aludir ao fato de que os professores, em sala de aula, não conseguem perceber sozinhos as necessidades e os próprios êxitos do estudante incluído.

Sobre a percepção dos professores quanto ao fato de a avaliação do aluno com deficiência e/NEE ocorrer de forma articulada, tem-se que: "É importante, pois o profissional de Educação Especial, na minha forma de pensar, possibilitará uma avaliação mais detalhada, minuciosa do aluno". (P1); "Acho que também se ganha em qualidade com isso, pelos mesmos motivos citados anteriormente" (P2); "É a melhor maneira de avaliar, pois avaliaremos o todo tendo a colaboração de um olhar mais especializado" (P4); "Torna a avaliação mais focada nas reais capacidades do aluno" (P5); "Ela se tornaria mais interessante se o profissional de Educação Especial estivesse junto na sala de aula" (P6); "Essencial diante das distintas capacidades e potencialidades que devem ser reconhecidas." (P7).

A avaliação é uma etapa de importância ímpar no processo educacional. As diversas técnicas avaliativas e metodologias a elas empregadas visam avaliar ao aluno de maneira qualitativa e quantitativa. Em se tratando de alunos com NEE, esta avaliação merece uma atenção especial, a qual é positiva quando realizada por profissionais que

\footnotetext{
${ }^{4}$ Ver Car, W.; Kemmis, S. Teoria crítica de la enseñanza: la investigación-acción en la formación del profesorado. Barcelona: Ediciones Martinez Roca, 1988.
} 
trabalham em conjunto. Pois, podem avaliar não apenas o resultado (professor), mas também a evolução deste aluno (profissional de Educação Especial). (P3)

Verifica-se que os docentes percebem a avaliação dos alunos com deficiência e/ou NEE realizada em parceria entre professores de Educação Especial e da classe comum uma atividade imprescindível, pelo fato de esses profissionais possuírem conhecimentos distintos, que podem se complementar, para mobilizar a aprendizagem dos alunos e, consequentemente, podem se complementar no processo de avaliação.

Como coloca P3, talvez, o professor consiga melhor avaliar o aluno no contexto da aprendizagem do conteúdo específico da disciplina, e o professor de Educação Especial consiga ter um olhar mais particular para aspectos cognitivos, sociais e físicos do desenvolvimento do estudante que mobiliza do trabalho docente articulado, sendo que juntos, como os professores afirmam, possa haver uma avaliação mais centrada no aluno, uma avaliação do todo.

Nessa avaliação de forma articulada, vale lembrar que existe, também, a ponderação sobre a própria prática docente, que não é referida pelos professores nesse item, e isso permite a interpretação de que poucos professores consideram a avaliação como um reflexo de sua prática. Porém, em outros momentos, alguns docentes, como P1, P3, P4, e P7, referiram que um trabalho em parceria permite repensar suas metodologias de ensino, suas práticas pedagógicas.

Ainda, o referido acima pela professora P6 apresenta algo bastante relevante no que diz respeito à avaliação, existindo uma proposta de trabalho docente articulado. No trabalho docente articulado, apesar de o professor de Educação Especial não necessitar estar sempre junto com o professor da classe comum em sala de aula, acredita-se que seja importante e necessário, em alguns momentos, o desenvolvimento da aula de forma articulada, colaborativa entre os docentes. Com isso, o professor de Educação Especial tem a possibilidade de perceber aspectos específicos do desenvolvimento dos alunos com deficiências e/ou necessidades educacionais especiais na classe comum, os quais o professor da classe comum, muitas vezes, não verifica e que podem ser importantes na avaliação, bem como no processo de aprendizagem do aluno com deficiência e/ou NEE.

Percebe-se, então, que, no trabalho docente articulado, em algum instante, devem acontecer os três momentos, ou seja: o planejar a aula, o desenvolvê-la e a avaliação do aluno com deficiência e/ou NEE e da prática docente de forma conjunta entre professores de Educação Especial e de classe comum.

Efetivar todos os momentos do trabalho docente articulado, entretanto, não é algo simples. Afirma-se isso tendo por base os escritos de Fontes (2008), Capellini (2004) e alguns momentos registrados no diário de campo, em que, mesmo havendo a proposição desse trabalho no IFFarroupilha - Campus São Borja, sua realização, de forma plena, nos três aspectos que envolvem essa prática, ainda pouco acontece. Isso, principalmente por não existirem momentos de planejamento articulado ou por estes existirem em um primeiro momento e, depois, não se conseguir mantê-los devido a outras tarefas dos docentes ou da própria professora de Educação Especial, o que ocorre também com o desenvolvimento da aula e da avaliação de forma articulada.

Pensando-se na educação profissional e tecnológica, questionaram-se os professores, também, sobre viabilidades e inviabilidades, pontos positivos e negativos da efetivação do trabalho docente articulado. Sobre isso, P4 não se manifestou. P1, P5 e P3 acreditam que não há empecilho para efetivação dessa prática e ressaltam como ponto positivo que "Torna possível a ação conjunta do conhecimento técnico do professor com a orientação do profissional de Educação Especial, para o melhor aproveitamento do conteúdo para com o aluno com NEE.” (P5); “[...] só tem a acrescentar, enriquecer muito no trabalho do professor em sala." (P1). "Os pontos positivos são vários, entre eles: troca de informações entre os profissionais; a colaboração mais efetiva visando à 
inclusão; uma visão mais norteadora à prática docente; uma atenção especial ao aluno com NEE." (P3).

Os aspectos ressaltados pelos docentes são o que se pensa como benefícios do trabalho docente articulado. Dos três professores acima, pode-se dizer que P3 é quem possui ou expressa ter uma visão mais completa acerca da Educação Especial numa perspectiva inclusiva e do trabalho docente articulado. Esse profissional é o único de todos os demais participantes da pesquisa que teve, em sua formação inicial, disciplinas referentes à Educação Especial, o que pode haver influenciado seus conhecimentos e percepções sobre a temática desse estudo. Como afirma Fontes (2008), aos professores que não tiveram, na formação inicial, nenhuma discussão sobre o ensino a pessoas com deficiência e/ou NEE, sobre o trabalho articulado, sua realização pode suscitar uma relação "desconcertante" e conflituosa.

Sobre as viabilidades e inviabilidades do trabalho docente articulado, P6 destacou que "Teoricamente, com a carga horária disponível para o planejamento, hoje na rede federal se torna mais fácil, porém, muitas vezes esse tempo não colabora para uma maior discussão e colaboração". Também P3 afirma que "Como ponto negativo, talvez, o maior dispêndio de tempo".

$\mathrm{Na}$ educação profissional e tecnológica, no IFFarroupilha - Campus São Borja, em tese, os docentes têm mais tempo para desenvolver, para preparar sua prática pedagógica, mas, conforme P6 relata, esse tempo é, muitas vezes, tomado pelo desempenho de distintas funções que os docentes assumem, como de coordenação, projetos, comissões e outras, além das aulas que ministram. Isso torna o tempo, na instituição, insuficiente para o diálogo entre os professores, para realização de um trabalho docente articulado.

Por outro lado, resgatando relatos do diário de campo, muitas vezes, percebe-se que, para alguns docentes, em média, quatro dos onze professores de A1, não é a falta de tempo que não colabora para realização de um trabalho docente articulado, mas sim a pouca expectativa que esses professores têm na educação e no sucesso de alunos com deficiência e/ou NEE nas escolas e classes comuns. Consequentemente, nota-se a pouca crença na eficiência do trabalho docente articulado, como se verifica na fala de P2: "Eu acho pouco provável ele (A1) aprender na sala de aula. A diferença dele pros outros é muito grande. O que a gente faz pode ajudar, mas não sei se adianta [...] Pra socialização sim é bom, mas pra aprender é complicado.” (Notas do diário de campo).

A partir da proposição do trabalho docente articulado com os professores do aluno A1 no IFFArroupilha, os registros do diário de campo denotam o considerável desgaste do profissional de Educação Especial por ser ele quem, geralmente, vai ao encontro do professor da classe comum para o estabelecimento de um trabalho em parceria. Esse resultado reafirma o que acontece também no ensino colaborativo, como se verifica na pesquisa de Zanata (2004).

A pouca iniciativa dos professores da classe comum em procurar o professor de Educação Especial torna-se negativa para o desenvolvimento do estudante com deficiência e/ou NEE, visto que, por vezes, o professor de Educação Especial sendo um só nas instituições de ensino não consegue encontrar, de forma diária ou semanalmente, todos os docentes de classe comum que possuem tais alunos. Então, é importante que também, o professor de classe comum procure o professor de Educação Especial para discutir sobre a aprendizagem e o desenvolvimento dos alunos que compartilham.

No entanto, às vezes, há o inverso, o professor de Educação Especial procura mais espaçadamente os professores de classe comum, devido a alguns docentes terem conseguido certa autonomia a partir dos planejamentos articulados com o professor de Educação Especial, para adaptar atividades e trabalhar com a especificidade do aluno com deficiência e/ou NEE, mobilizando assim a aprendizagem dele.

Outros docentes não procuram dialogar e trocar conhecimentos por depositarem parcas expectativas na aprendizagem do estudante A1, foco do trabalho docente articulado, como se 
percebe na colocação de P2: "É difícil. Acredito que o ambiente de sala de aula serve mais para socialização do que como local de aprendizagem [...]”. Essas situações não motivam o docente da classe comum ao diálogo, e isso faz surgir emoções ou sentimentos como frustração e desânimo no profissional de Educação Especial que busca essa parceria, o que prejudica a efetivação da Educação Especial nas instituições regulares de ensino, podendo mobilizar relações conflituosas entre os docentes, como identificado na pesquisa de Fontes (2008).

O fato acima relatado revela, também, algumas situações desconcertantes: a existência de conflitos de pensamentos, consequentemente, de atitudes no que tange à Educação Especial numa perspectiva inclusiva. Como a maioria dos onze professores de A1 não teve, em sua formação inicial, disciplinas que tratassem da inclusão educacional escolar de alunos com deficiências e/ou necessidades educacionais especiais, tampouco sobre ensino colaborativo, esses docentes têm e tiveram sentimentos de insegurança, angústia, ansiedade, reiterando o apontado por Naujorks, Pletsch e Kempfer (2000), referente à inclusão de alunos com deficiência e/ou NEE.

Outro aspecto que torna o trabalho docente articulado uma atividade complexa são as especificidades das disciplinas do Ensino Médio e por esse nível de ensino estar integrado ao ensino técnico. Frente a essas especificidades, o professor de Educação Especial, com formação para atender, principalmente, aos anos iniciais, muitas vezes, apresenta dificuldades para conseguir colaborar efetivamente com o professor da classe comum. Assim, torna-se necessário parceria consistente, comprometimento e certo período de tempo para que o docente de Educação Especial consiga abstrair alguns aspectos das disciplinas técnicas e melhor auxiliar o professor da classe comum.

Percebe-se que, para o trabalho docente articulado acontecer, faz-se necessário um período maior de tempo destinado à articulação dos saberes e das práticas entre os docentes de Educação Especial e da classe comum, e, ainda, a existência de mais profissionais, principalmente de Educação Especial, mas também de mais professores por instituição. Conforme P7 explicita sobre as viabilidades e inviabilidades deste trabalho, "É relevante e possível, mas percebo ser relevante [haver] mais profissionais com qualificação específica para tanto".

Além do aumento quantitativo dos docentes, estes precisam estar abertos ao diálogo, precisam discutir, em sua formação na instituição de ensino, a importância e necessidade de uma articulação dos planejamentos e das práticas entre professores de Educação Especial e os da classe comum. Também, entende-se como essencial que discussões sobre essa articulação e sobre o trabalho docente articulado aconteçam na formação inicial dos professores. $\mathrm{O}$ trabalho docente articulado precisa ser debatido e pleiteado na formação dos professores, pois, com isso, acredita-se que poderá se tornar efetivo no contexto educacional.

$\mathrm{Na}$ maioria dos estabelecimentos de ensino profissional e tecnológico, existe uma quantidade de docentes que possibilita uma melhor distribuição da carga horária de aula, o que, na Educação Básica, é mais difícil de acontecer. Por isso, considera-se que, além da contratação de mais docentes de Educação Especial, há a necessidade (principalmente na Educação Básica) de investimento em mais professores da classe comum, pois, para o trabalho docente articulado ocorrer, é preciso que esses profissionais não estejam na instituição somente em sala de aula ou sala de recursos, mas tenham a possibilidade de trocar saberes, percepções, ações. Tudo isso, contudo, implica a aplicação de maior valor econômico na educação brasileira.

Inclusive P2 menciona o trabalho docente articulado como mais relevante aos anos iniciais do que aos anos finais do Ensino Fundamental. Corrobora-se a afirmação do professor, pois é nesse período que aspectos basilares para toda a escolarização precisam ser desenvolvidos e, hoje, muitas vezes, não o são, como a leitura, escrita e o cálculo. Isso acaba fazendo com que, no Ensino Médio, muitos alunos desistam e/ou tenham problemas de aprendizagem, o que exige a retomada desses aspectos. 
Acredita-se que se o trabalho docente articulado ou mesmo o ensino colaborativo acontecer nos anos iniciais do Ensino Fundamental, os alunos com deficiência e/ou NEE poderão chegar às séries finais deste e ao Ensino Médio imbuídos de conhecimentos essenciais para a aprendizagem de conceitos que esses níveis de ensino exigem.

A partir do estudo realizado reitera-se a afirmação de que tanto nos anos iniciais do Ensino Fundamental quanto nos anos finais, no Ensino Médio (ou médio integrado ao técnico), faz-se essencial um trabalho em parceria entre professor de Educação Especial e professor da classe comum. Isso, porque, como afirma P4, esses professores sempre terão conhecimentos e experiências distintas, que podem se complementar, de alguma forma, na promoção da aprendizagem, especificamente, dos alunos com deficiência e/ou NEE, mas também de todos os estudantes.

Ainda sobre o trabalho pedagógico com alunos com deficiência e/ou NEE, o professor P3 pontuou que "O essencial para mim é troca de informações entre os profissionais envolvidos no trabalho e o acompanhamento minucioso do processo de inclusão e aprendizagem”. Para P4 e P6, é importante "Pensar em atividades que busquem incluir o aluno na turma [...] Acredito que o trabalho conjunto entre professores e profissionais da área de Educação Especial é peça chave e fundamental para o sucesso do aluno.” (P4); “Adaptar o conteúdo ao nível de aprendizagem do aluno, orientação e acompanhamento constante do profissional da Educação Especial” (P6).

Nas falas dos três docentes, verifica-se o trabalho conjunto, a troca de informações e experiências como importantes para a promoção da aprendizagem dos alunos, bem como aparecem como mobilizadores do trabalho docente articulado. Isso novamente reitera a importância de se desenvolver essa prática diante da realidade da Educação Especial nas escolas e classes comuns, como os próprios professores têm apontado em suas colocações anteriores.

Para P4, é relevante a realização de atividades que façam o aluno com deficiência e/ou NEE sentir-se parte da turma, pois é imprescindível que esse estudante sinta-se bem, esteja à vontade na turma, na instituição, para ser possível mobilizar sua aprendizagem (Carvalho, 2010).

Por fim, a colocação acima remete ao fato de que, na realização do trabalho docente articulado, é preciso ter cuidado, principalmente quando do desenvolvimento da aula de forma compartilhada entre o professor de Educação Especial e o professor da disciplina, para que o professor de Educação Especial não fique somente com o aluno com deficiência e/ou NEE. Isso pode fazer com que o próprio estudante não se sinta à vontade, tornando o desenvolvimento da aula de forma conjunta entre os docentes mais um empecilho do que um auxílio à sua aprendizagem.

\section{Considerações Finais}

A partir dos dados coletados, pode-se dizer que o trabalho docente articulado se mostra uma prática bastante exequível aos sete professores que participaram deste estudo, o que demonstra um indicativo favorável para sua possibilidade de efetivação. No entanto, sabe-se que para, essa prática conjunta acontecer de fato, a estrutura organizacional das instituições de ensino e as práticas pedagógicas necessitam ser repensadas, pois serão imprescindíveis mais professores, melhores condições de trabalho e, principalmente, tempo em conjunto para planejarem, dialogarem sobre as proposições, o desenvolvimento, os anseios, as expectativas, as emoções e sentimentos em relação aos alunos com deficiência e/ou NEE.

Os professores participantes deste estudo mencionaram que os diálogos com o profissional de Educação Especial lhes auxiliaram nas reflexões, ações e adaptações realizadas para o aluno foco do trabalho docente articulado. Mencionaram, ainda, que percebem o momento de planejamento articulado entre os docentes como importante e essencial diante da inclusão educacional escolar de alunos com deficiência e/ou NEE. 
Concernente ao desenvolvimento da aula de forma colaborativa, a maioria dos participantes do estudo acredita que o trabalho de forma colaborativa seja favorável aos alunos e à prática docente em sala de aula. Porém, somente a professora P6 solicitou efetivar tal ação por achar que auxiliaria no desenvolvimento de A1. O desenvolvimento da aula de forma conjunta aconteceu somente uma vez, porque, devido a atividades pessoais dela, seu horário de aula mudou para um dia da semana em turno que a profissional de Educação Especial não se encontrava na instituição.

O fato acima referido indica a necessidade de mais profissionais de Educação Especial na educação profissional e tecnológica, caso o trabalho docente articulado seja a prática metodológica utilizada. A educação profissional e tecnológica forma alunos em diversas áreas do conhecimento, e o professor de Educação Especial necessita de constante diálogo com o professor da classe comum e certo período de tempo para poder assimilar alguns aspectos técnicos que o auxiliem a melhor promover, junto ao professor da classe comum, a aprendizagem dos alunos com deficiência e/ou NEE e dos demais. Com maior número de profissionais de Educação Especial nas instituições, estes poderiam formar o corpo docente de cada curso ou eixo tecnológico, podendo realizar um trabalho articulado mais eficiente.

Para a realização do trabalho docente articulado não ser uma prática desgastante para o professor da classe comum ou para o professor de Educação Especial, é preciso haver comprometimento de ambos. Para tal, na formação inicial e continuada, a temática do trabalho docente articulado precisa ser abordada, bem como o ensino colaborativo.

Algumas dificuldades na realização do trabalho docente articulado são apontadas pelos professores participantes do estudo, mas de maneira tímida, o que evidencia a necessidade de encontros de discussão acerca do trabalho docente articulado: o que ele propõe, como vem se materializando e como pode ser melhorado para potencializar o saber/fazer de todos os professores diante da educação de alunos com deficiência e/ou NEE nas escolas comuns.

Por fim, sabe-se que a efetivação do trabalho docente articulado necessita a superação de vários obstáculos, a começar pela a própria conjuntura social na qual a educação está inserida e organizada, pois os documentos legais e as políticas não garantem por si só tal prática com vistas à inclusão educacional escolar. Entretanto, acredita-se no seu potencial para mobilizar a aprendizagem, principalmente dos alunos com deficiência e/ou NEE, frente à proposta de Educação Especial na perspectiva da educação inclusiva.

\section{Referências}

Assis, C. P., Mendes, E. G., \& Almeida, M. A. (2011). Ensino colaborativo: um relato de experiência sobre o desenvolvimento de parceria colaborativa. Educere et Educare - Revista de Educaşão, Vol. $6-\mathrm{N}^{\mathrm{o}} 11-1^{\mathrm{o}}$ Semestre.

Bardin, L. (2008). Análise de Conteúdo. Lisboa/Portugal: Edições 70.

Brasil. (1996). Lei no 9.394, de 20 de dezembro de 1996. Estabelece as Diretrizes e Bases da Educação Nacional. Diário Oficial da União, Brasília/Brasil.

Brasil. (2001). Diretrizes Nacionais da Educação Especial na Educação Básica. Brasília/Brasil. MEC/SEESP.

Brasil. (2008). Ministério da Educação. Secretaria da Educação Especial. Política Nacional de Educação Especial na Perspectiva da Educação Inclusiva. MEC/SEESP, Brasília/Brasil.

Brasil. (2009). Resolução no 4, de 2 de outubro de 2009. Institui Diretrizes Operacionais para o Atendimento Educacional Especializado na Educação Básica, modalidade Educação Especial. Resolução CNE/CEB 4/2009. Diário Oficial da União, Brasília/Brasil. 
Capellini, V. L. M. F. (2004) Avaliação das possibilidades do ensino colaborativo no processo de inclusão escolar do aluno com deficiência mental. 2004. Tese (Doutorado em Educação Especial) - Centro de Educação e Ciências Humanas, Universidade Federal de São Carlos, São Carlos/Brasil.

Carvalho, R. E. (2006). Educação inclusiva: com os pingos nos "is". 4a ed. Porto Alegre/Brasil: Mediação.

Carvalho, R. E. (2010). Educação inclusiva: a reorganiz̧ação do trabalbo pedagógico. $3^{\mathrm{a}}$. ed. Porto Alegre: Mediação.

Costas, F. A. T., \& Tambara, K. G. (2013). A nova política nacional de educação especial no Brasil e suas decorrências para o atendimento de alunos com transtornos de aprendizagem. In XII Congresso Internacional Galego-Português de Psicopedagogia, Braga, Portugal. Atas do XII Congresso Internacional Galego-Português de Psicopedagogia. Braga, Portugal: CIED-Centro de Investigação em Educação, Instituto de Educação, Universidade do Minho, Portugal, 2013. v.1. p.423 - 438

Devens, W. M. (2007). Trabalho colaborativo crítico como dispositivo para práticas educacionais inclusivas. Dissertação (Mestrado em Educação)- Centro de educação, Universidade Federal do Espírito Santo.

Fontes, R. (2008). Educação inclusiva no município de Niterói (RJ): Das propostas oficiais às experiências em sala de aula - o desafio da bidocência. Tese (Doutorado em Educação). Programa de Pós-Graduação da Universidade do Estado do Rio de Janeiro.

Instituto Federal Farroupilha. Resolução 039, de 9 de setembro de 2011. Programa de Ações Afirmativas para os cursos Técnicos de Nível Médio e Superiores, presenciais e a distância do Instituto Federal de Educação, Ciência e Tecnologia Farroupilha.. Disponível em: http://www.iffarroupilha.edu.br/site/conteudo.php?cat=11\&sub=1181. Acesso em: 22 de jan. de 2013.

Mendes, E. G. (2006) Colaboração entre ensino regular e especial: o caminho do desenvolvimento pessoal para a inclusão escolar. In: Manzini E. J (org). Inclusão e acessibilidade. (p. 29-41) Marília: ABPEE.

Naujorks, M. I., Pletsch, M. D., \& Kempfer, G. L. (2000). Stress ou burnout: A realidade frente a inclusão. Cadernos de Educação Especial, 15, 67-74.

Sant'ana, I. M. (2005). Educação inclusiva: Concepções de professores e diretores. Psicologia em Estudo, 10 (2), 227-234. http:/ / dx.doi.org/10.1590/S1413-73722005000200009

Zanata, E. M. (2004) Práticas pedagógicas inclusivas para alunos surdos numa perspectiva colaborativa. Tese (Doutorado em Educação Especial) - Centro de Educação e Ciências Humanas, Universidade Federal de São Carlos, São Carlos. 


\section{Sobre o Autoras}

\section{Fabiane Adela Tonetto Costas}

Professora Associada do Departamento de Fundamentos da Educação da Universidade Federal de Santa Maria-UFSM

fabicostas@gmail.com

Pesquisadora na área de Educação Especial, líder do Grupo de Estudos e Pesquisas em Psicologia da Educação e Educação Inclusiva - GEPEIN, o qual desenvolve pesquisas fundamentadas principalmente pela Psicologia Histórico-Cultural e que abrangem a Educação Especial e a Educação Inclusiva tanto na educação básica como na educação superior. É autora e co-autora organizadora das seguintes obras Formação de conceitos em crianças com necessidades educacionais especiais:contribuições da Teoria Histórico-Cultural e Educação, educação especial e inclusão: fundamentos, contexto e práticas.

\section{Cláucia Honnef}

Professora Externa do Curso de Educação Especial- EAD da Universidade Federal de Santa Maria; Professora de Educação Especial da Rede Municipal de Ensino de Agudo/RS profclaucia@gmail.com

Professora de Educação Especial da Rede Municipal de Ensino de Agudo/RS e Professora Externa do Curso de Educação Especial- EAD da Universidade Federal de Santa Maria. Foi Professora Temporária do Instituto Federal Farroupilha- Campus São Borja/RS (2012-2013). Especialista em Gestão Educacional (2011); Mestre em Extensão Rural (2012); Mestre em Educação (2013), pela Universidade Federal de Santa Maria. Seus principais temas de pesquisa tratam do trabalho docente articulado, ensino colaborativo, Educação Especial e inclusão educacional escolar e educação inclusiva e formação de professores.

\section{Sobre as Editoras Convidadas}

\section{Márcia Denise Pletsch}

Professora do Programa de Pós-Graduação em Educação, Contextos Contemporâneos e Demandas Populares (PPGEduc) na linha de pesquisa Estudos Contemporâneos e Práticas Educativas e do Departamento Educação e Sociedade da Universidade Federal Rural do Rio de janeiro. marciadenisepletsch@gmail.com

A autora é pesquisadora na área de Educação Especial, atuando na formação de professores e de novos pesquisadores. É líder do Grupo de Pesquisa (CNPq) Observatório de Educação Especial e inclusão escolar: práticas curriculares e processos de ensino e aprendizagem e, por meio de convênio interinstitucional entre a UFRRJ e a Universidade do Estado do Rio de Janeiro (UERJ), também é líder do grupo de pesquisa Inclusão e aprendizagem de alunos com necessidades educacionais especiais: práticas pedagógicas, cultura escolar e aspectos psicossociais. Atualmente, coordena o Programa Observatório da Educação da CAPES com projeto de pesquisa em rede na área de deficiência intelectual envolvendo a Universidade Estadual de Santa Catarina (UDESC), Universidade do Vale do Itajaí (UNIVALI); e coordena também pesquisas financiadas pela FAPERJ na área de deficiência múltipla. É autora do livro "Repensando a inclusão escolar: diretrizes políticas, práticas curriculares e deficiência intelectual" e, em colaboração com Rosana Glat, do livro "Inclusão escolar de alunos com necessidades especiais". Organizou em parceria com outros pesquisadores, entre outros, os livros "Estratégias educacionais diferenciadas para alunos com necessidades especiais" e "Educação 
Especial e inclusão escolar: reflexões sobre o fazer pedagógico". Tem mais de vinte artigos publicados em revistas científicas nacionais e internacionais.

\section{Geovana Mendonça Lunardi Mendes}

Professora do Programa de Pós-Graduação em Educação e do Departamento de Pedagogia da Universidade do Estado de Santa Catarina (PGE-UDESC)

geolunardi@gmail.com

A autora é pesquisadora na área de Educação Especial e dos Estudos Curriculares. Realizou PósDoutorado na Argentina e nos Estados Unidos da América, na área de Currículo e Novas Tecnologias, na Universidad de San Andres em Buenos Aires e em Ashland University, em Ohio. É pesquisadora coordenadora de diferentes projetos de investigação e participa como pesquisadora convidada em projetos de pesquisa nacionais e internacionais. Suas pesquisas e produções têm sido voltadas para área de Currículo e práticas escolares, em especial, as questões relativas as mudanças, novas tecnologias e inovações curriculares no espaço escolar, e também as práticas curriculares voltadas a inclusão de sujeitos com deficiência. Atualmente é a Coordenadora Nacional do Consórcio "Educação e Diversidade" do programa CAPES. FIPSE de Cooperação Internacional, envolvendo a Universidade Federal Rural do Rio de Janeiro, no Brasil e Georgetown College, Ashland University e Brighman Young University nos Estados Unidos e também do Projeto de Pesquisa: Aulas conectadas: mudanças curriculares e aprendizagem colaborativa nas escolas do PROUCA em Santa Catarina, com financiamento do CNPq e do Projeto Observatório de Práticas Escolares com financiamento da FAPESC. É coordenadora do Programa de Pós-graduação em Educação, Mestrado e Doutorado, da FAED, UDESC. Coordena o Observatório da Educação: Tablets, Computadores e Laptops, aprovado no Edital OBEDUC/CAPES. Entre suas atuais produções podem ser destacadas o livro intitulado "Objetos Pedagógicos: uma experiência inclusive em oficinas de Artes", em parceria com mais duas autoras e a organização do Livro "Deficiência e Escolarização: novas perspectivas de analise", hoje na segunda edição. É autora de inúmeros capítulos e artigos publicados em periódicos. 


\title{
DOSSIẾ
Educação Especial: Diferenças, Currículo e Processos de Ensino e Aprendizagem II arquivos analíticos de políticas educativas
}

Volume 23 Número 35
16 de março de 2015
ISSN 1068-2341

\begin{abstract}
(c)
SOMERERIGHISRESERVED O Copyright e retido pelo/a o autor/a (ou primeiro co-autor) que outorga o direito da primeira publicação à revista Arquivos Analíticos de Políticas Educativas. Más informação da licença de Creative Commons encontram-se em http://creativecommons.org/licenses/by-nc-nd/2.5. Qualquer outro uso deve ser aprovado em conjunto pelo/s autor/es e por AAPE/EPAA. AAPE/EPAA é publicada por Mary Lou Fulton Institute Teachers College da Arizona State University. Os textos publicados em AAPE são indexados por CIRC (Clasificación Integrada de Revistas Científicas, Espanha) DIALNET (Espanha),Directory of Open Access Journals, Education Full Text (H.W. Wilson), EBSCO Education Research Complete, , ERIC, , QUALIS A2 (Brasil), SCImago Journal Rank; SCOPUS, SOCOLAR (China). Contribua com comentários e sugestões a http://epaa.info/wordpress/ou para Gustavo E. Fischman fischman@asu.edu.
\end{abstract}

Curta a nossa comunidade EPAA's Facebook https://www.facebook.com/EPAAAAPE e Twitter feed@epaa_aape. 


\section{arquivos analíticos de políticas educativas conselho editorial}

Editor: Gustavo E. Fischman (Arizona State University) Editores Associados: Rosa Maria Bueno Fisher e Luis A. Gandin

(Universidade Federal do Rio Grande do Sul)

Dalila Andrade de Oliveira Universidade Federal de Minas Gerais, Brasil

Paulo Carrano Universidade Federal Fluminense, Brasil

Alicia Maria Catalano de Bonamino Pontificia Universidade Católica-Rio, Brasil

Fabiana de Amorim Marcello Universidade Luterana do Brasil, Canoas, Brasil

Alexandre Fernandez Vaz Universidade Federal de Santa Catarina, Brasil

Gaudêncio Frigotto Universidade do Estado do Rio de Janeiro, Brasil

Alfredo M Gomes Universidade Federal de Pernambuco, Brasil

Petronilha Beatriz Gonçalves e Silva Universidade Federal de São Carlos, Brasil

Nadja Herman Pontificia Universidade Católica -Rio Grande do Sul, Brasil

José Machado Pais Instituto de Ciências Sociais da Universidade de Lisboa, Portugal

Wenceslao Machado de Oliveira Jr. Universidade Estadual de Campinas, Brasil
Jefferson Mainardes Universidade Estadual de Ponta Grossa, Brasil

Luciano Mendes de Faria Filho Universidade Federal de Minas Gerais, Brasil

Lia Raquel Moreira Oliveira Universidade do Minho, Portugal

Belmira Oliveira Bueno Universidade de São Paulo, Brasil

António Teodoro Universidade Lusófona, Portugal

Pia L. Wong California State University Sacramento, U.S.A

Sandra Regina Sales Universidade Federal Rural do Rio de Janeiro, Brasil

Elba Siqueira Sá Barreto Fundação Carlos Chagas, Brasil

Manuela Terrasêca Universidade do Porto, Portugal

Robert Verhine Universidade Federal da Bahia, Brasil

Antônio A. S. Zuin Universidade Federal de São Carlos, Brasil 


\section{education policy analysis archives editorial board \\ Editor Gustavo E. Fischman (Arizona State University) \\ Associate Editors: Audrey Amrein-Beardsley (Arizona State University), Rick Mintrop, (University of California, Jeanne M. Powers (Arizona State University)}

Jessica Allen University of Colorado, Boulder

Gary Anderson New York University

Michael W. Apple University of Wisconsin, Madison

Angela Arzubiaga Arizona State University

David C. Berliner Arizona State University

Robert Bickel Marshall University

Henry Braun Boston College

Eric Camburn University of Wisconsin, Madison

Wendy C. Chi* University of Colorado, Boulder

Casey Cobb University of Connecticut

Arnold Danzig Arizona State University

Antonia Darder University of Illinois, UrbanaChampaign

Linda Darling-Hammond Stanford University

Chad d'Entremont Strategies for Children

John Diamond Harvard University

Tara Donahue Learning Point Associates

Sherman Dorn University of South Florida

Christopher Joseph Frey Bowling Green State University

Melissa Lynn Freeman* Adams State College

Amy Garrett Dikkers University of Minnesota

Gene V Glass Arizona State University

Ronald Glass University of California, Santa Cruz

Harvey Goldstein Bristol University

Jacob P. K. Gross Indiana University

Eric M. Haas WestEd

Kimberly Joy Howard* University of Southern California

Aimee Howley Ohio University

Craig Howley Ohio University

Steve Klees University of Maryland

Jaekyung Lee SUNY Buffalo
Christopher Lubienski University of Illinois, UrbanaChampaign

Sarah Lubienski University of Illinois, UrbanaChampaign

Samuel R. Lucas University of California, Berkeley

Maria Martinez-Coslo University of Texas, Arlington

William Mathis University of Colorado, Boulder

Tristan McCowan Institute of Education, London

Heinrich Mintrop University of California, Berkeley

Michele S. Moses University of Colorado, Boulder

Julianne Moss University of Melbourne

Sharon Nichols University of Texas, San Antonio

Noga O'Connor University of Iowa

João Paraskveva University of Massachusetts, Dartmouth

Laurence Parker University of Illinois, UrbanaChampaign

Susan L. Robertson Bristol University

John Rogers University of California, Los Angeles

A. G. Rud Purdue University

Felicia C. Sanders The Pennsylvania State University

Janelle Scott University of California, Berkeley

Kimberly Scott Arizona State University

Dorothy Shipps Baruch College/CUNY

Maria Teresa Tatto Michigan State University

Larisa Warhol University of Connecticut

Cally Waite Social Science Research Council

John Weathers University of Colorado, Colorado Springs

Kevin Welner University of Colorado, Boulder

Ed Wiley University of Colorado, Boulder

Terrence G. Wiley Arizona State University

John Willinsky Stanford University

Kyo Yamashiro University of California, Los Angeles

* Members of the New Scholars Board 


\section{archivos analíticos de políticas educativas consejo editorial}

Editor: Gustavo E. Fischman (Arizona State University)

Editores. Asociados Alejandro Canales (UNAM) y Jesús Romero Morante (Universidad de Cantabria)

Armando Alcántara Santuario Instituto de Investigaciones sobre la Universidad y la Educación, UNAM México

Claudio Almonacid Universidad Metropolitana de Ciencias de la Educación, Chile

Pilar Arnaiz Sánchez Universidad de Murcia, España

Xavier Besalú Costa Universitat de Girona, España

Jose Joaquin Brunner Universidad Diego Portales, Chile

Damián Canales Sánchez Instituto Nacional para la Evaluación de la Educación, México

María Caridad García Universidad Católica del Norte, Chile

Raimundo Cuesta Fernández IES Fray Luis de León, España

Marco Antonio Delgado Fuentes Universidad Iberoamericana, México

Inés Dussel FLACSO, Argentina

Rafael Feito Alonso Universidad Complutense de Madrid, España

Pedro Flores Crespo Universidad Iberoamericana, México

Verónica García Martínez Universidad Juárez Autónoma de Tabasco, México

Francisco F. García Pérez Universidad de Sevilla, España

Edna Luna Serrano Universidad Autónoma de Baja California, México

Alma Maldonado Departamento de Investigaciones Educativas, Centro de Investigación y de Estudios Avanzados, México

Alejandro Márquez Jiménez Instituto de Investigaciones sobre la Universidad y la Educación, UNAM México

José Felipe Martínez Fernández University of California Los Angeles, USA
Fanni Muñoz Pontificia Universidad Católica de Perú

Imanol Ordorika Instituto de Investigaciones Economicas - UNAM, México

Maria Cristina Parra Sandoval Universidad de Zulia, Venezuela

Miguel A. Pereyra Universidad de Granada, España

Monica Pini Universidad Nacional de San Martín, Argentina

Paula Razquin UNESCO, Francia

Ignacio Rivas Flores Universidad de Málaga, España

Daniel Schugurensky Arizona State University

Orlando Pulido Chaves Universidad Pedagógica Nacional, Colombia

José Gregorio Rodríguez Universidad Nacional de Colombia

Miriam Rodríguez Vargas Universidad Autónoma de Tamaulipas, México

Mario Rueda Beltrán Instituto de Investigaciones sobre la Universidad y la Educación, UNAM México

José Luis San Fabián Maroto Universidad de Oviedo, España

Yengny Marisol Silva Laya Universidad Iberoamericana, México

Aida Terrón Bañuelos Universidad de Oviedo, España

Jurjo Torres Santomé Universidad de la Coruña, España

Antoni Verger Planells University of Amsterdam, Holanda

Mario Yapu Universidad Para la Investigación Estratégica, Bolivia 